\title{
Process Parameters Influence on Impact Toughness and Microstructure of Pre-heat Treated Friction Welded 15CDV6 Alloy Steel
}

\author{
D. Raji Reddy ${ }^{\mathrm{a},{ }^{*}}$, P.Laxminarayana ${ }^{\mathrm{b}}$, G.C.M. Reddy ${ }^{\mathrm{c}}$, G.M.S.Reddy ${ }^{\mathrm{d}}$ \\ ${ }^{a}$ Research Scholar, Department of Mechanical Engineering, Osmania University,Hyderabd-500007, India \\ ${ }^{b}$ Department of Mechanical Engineering, Osmania University, Hyderabd-500007, India \\ ${ }^{c}$ Department of Mechanical Engineering, C.B.I.T (MGIT on Depu.)., Hyderabad-50075, India \\ ${ }^{d}$ Scientist 'G' Defence Metallurgical Research Laboratory[DMRL], MJG group Hyderabad 500058, India
}

\begin{abstract}
Friction welding is a solid state joining process the joints are formed by utilizing the heat generated by friction. This paper discusses the importance of impact toughness in friction welded components and the effect of various process parameters on impact toughness. The process parameters considered in this research work are friction force, Forge force, rotational speed and burn-off length for the 15CDV6 alloy steel and the Impact toughness is optimized to establish the weld quality using the Taguchi experimental design technique with an orthogonal array of $\mathrm{L}_{9}$, ANOVA. The effects of process parameters are discussed in detail based on the values obtained in the ANOVA and micro structural observations.
\end{abstract}

Index Terms: Friction welding, 15CDV6 Alloy steel, Impact toughness, Microstructure.

(C) 2016 Published by MECS Publisher. Selection and/or peer review under responsibility of the Research Association of Modern Education and Computer Science.

\section{Introduction}

Friction welding is one of the solid state joining process by which the quality welded products can be produced, this method of joining has gained more importance in the fabrication industry. In the field of welding, the weld quality mainly depends on the type of welding, mechanical properties of the weld metal and heat affected zone (HAZ) which in turn is influenced by metallurgical characteristics and chemical compositions of the weld [1]. The advantages of this friction welding process include high reproducibility, less production time and low energy input. In this method the joints are formed by heat generated due to friction. The friction is achieved in this process by rotating one component at high revolutions per minute (rpm) in contact with a stationary component by applying axial pressure during rotation the temperature at the interface is increased

* Corresponding author.

E-mail: address: 
until material reach the plastic state.

\section{Nomenclature}

RS Rotational Side

SS Stationary side

The heat in friction welding is generated by conversion of mechanical energy into thermal energy at the interface of work pieces during rotation under pressure [3,4]. The simple set up of the friction welding machine is shown in Figure1. At a precise moment, the rotation is stopped and axial forging force is then applied between the two components [2]. Friction welding consistently provides high-strength, defect free joints and high productivity because of these advantages this welding technique has become the important for the manufacture of some of the cutting tools such as drills, reamers and milling cutters, and pump shafts and also in the industries like aeronautical engineering, automobile engineering, submarine industry and heavy industry. Friction welding consists the parameters such as friction force, friction time, forge force (upset force), upset time, temperature measurement, burn off length, and rotational speed are the most important parameters, in this welding process the quality and strength of the welds depend on the proper selection of these parameters.

In this study for the material 15CDV6 alloy steel the parameters friction force, forge force, rotational speed and burn off length were considered to optimize the mechanical properties for good quality of welds. This material is widely used by defence for the missiles rocket motor casing applications. The rods are welded with friction welding to missiles rocket motor casings and the other typical applications of 15CDV6 alloy steel material includes roll cages, rocket motor casings, track and push rods, uprights, pressure vessels, sub frames, wish bones, suspension components, and motor sport applications. The literature pertaining to this material not available in the open literature, the components made up of this material should withstand the shock loads the impact properties of the joints are necessary [8] in the above field of applications, because of its importance this material is chosen for my research work as similar materials friction welded joints. Joints of similar and dissimilar combinations are employed in different applications requiring various mechanical properties like hardness, tensile strength, brittleness, malleability etc and also to save cost incurred towards scared materials [12].

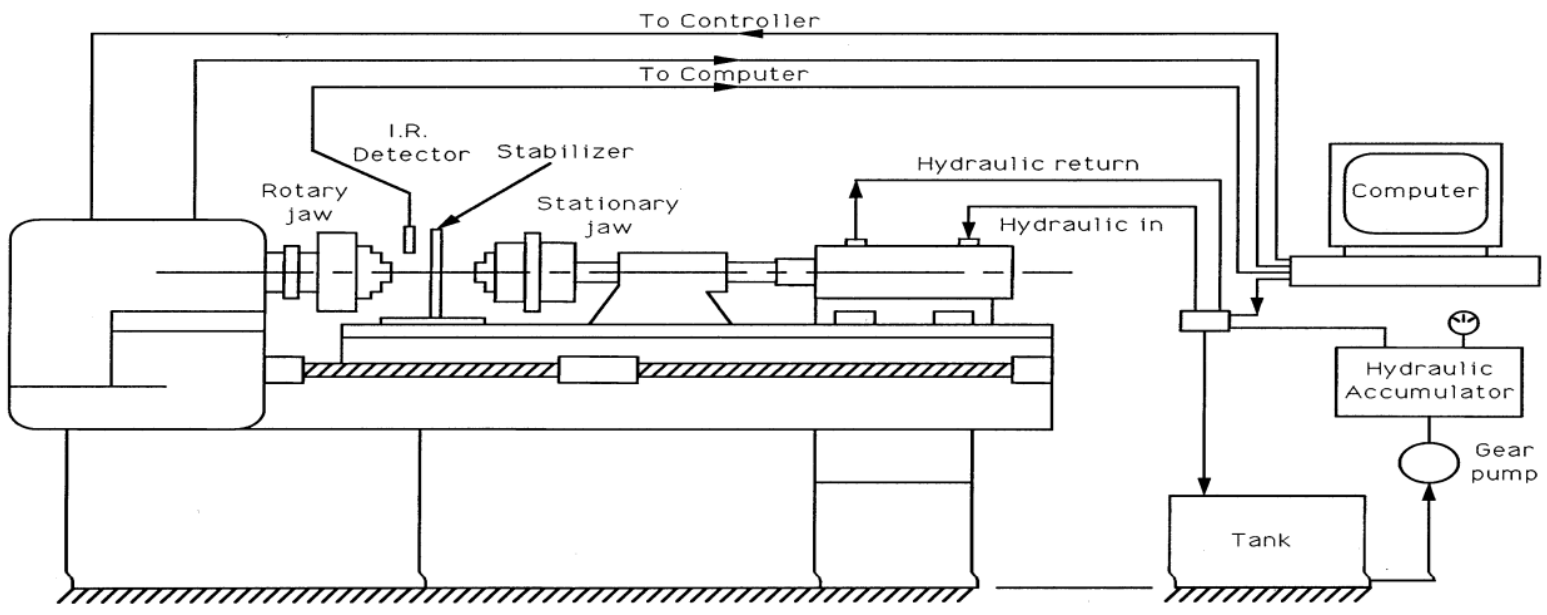

Fig.1. Continuous Drive Friction Welding Machine Setup

The Friction welding process can be divided into three different stages, stage I-III [5]. 
Stage I: Is the friction stage at this stage wear and seizure occurs due to the combined effect of coulomb friction and sticking force this causes the rapid rise of interface temperature as a result the yield strength decreases, for good weld the temperature rise at the interface should be sufficiently high above $\left(400^{\circ} \mathrm{C}\right)$ this ensures adequate plastic deformation. Towards the end of this stage a large amount flash flow occurs, the friction force and spindle speed plays important role in rising the temperature at the interface.

Stage II: Adiabatic heating due to plastic deformation helps in retaining the interface temperature due to the setting of the dynamic balance between heat generation and heat conduction, and the plastic deformation occurs continuously at constant rate with the influence of friction force. This stage is dependent on the burn off length, and its duration is larger with the larger burn off length.

Stage III: In this stage the parts are suddenly brought to rest and a forge force is applied. The forge force is always higher than the friction force, sound joints are achieved in this stage. The axial reduction depends not only on the magnitude of forge force but also on the duration of the burn off length in stage II.

\section{Experimental Work}

The material 15CDV6 alloy steel round rods of length $60 \mathrm{~mm}$ and diameter $17 \mathrm{~mm}$ were machined out from $20 \mathrm{~mm}$ thick plates and these round rods are pre-heat treated for hardening and tempering processes as shown in table 1, the heat treatment process will make the steel an important structural product [8]. The pre-heat treatment process of hardening develops the high hardness, wear resistance, strength and toughness in the material, but also at the same time makes the material ductile, to remove the ductility in the pre-heat treated hardening process of this material a further heat treatment process is applied which is called tempering. The chemical composition and mechanical properties of the base material is shown in table 2 and table 3 .

Table 1. Heat Treatment Process

\begin{tabular}{cccc}
\hline Process & Temperature $\left({ }^{\mathbf{0}} \mathbf{C}\right)$ & Type of cooling & Time $($ Min $)$ \\
\hline Hardening & 975 & Forced fan air cooling & 30 \\
Tempering & 650 & Forced fan air cooling & 60 \\
\hline
\end{tabular}

Table 2. Chemical Composition of the 15CDV6 Alloy Steel

\begin{tabular}{lllllllll}
\hline Element & $\mathbf{C}$ & $\mathbf{S i}$ & $\mathbf{M n}$ & $\mathbf{S}$ & $\mathbf{P}$ & $\mathbf{C r}$ & $\mathbf{M}_{\mathbf{0}}$ & $\mathbf{V}$ \\
Maximum & 0.18 & 0.20 & 1.10 & 0.015 & 0.020 & 1.50 & 1.00 & 0.30 \\
\hline
\end{tabular}

Table 3. Mechanical Properties of the 15CDV6 Alloy Steel

\begin{tabular}{ccccc}
\hline $\begin{array}{c}\text { condition } \\
1.7734 .2\end{array}$ & $\mathbf{0 . 2 \%}$ proof stress & Tensile strength & Elongation & hardness \\
(annealed) & - & - & - & $197 \mathrm{HB}$ \\
1.7734 .4 & $550 \mathrm{mp}_{\mathrm{a}} \min$ & $700 \mathrm{mp}_{\mathrm{a}} \min$ & $13 \% \mathrm{~min}$ & - \\
1.7734 .5 & $790 \mathrm{mp}_{\mathrm{a}} \min$ & $980-1180 \mathrm{mp}_{\mathrm{a}} \min$ & $11 \% \mathrm{~min}$ & - \\
1.7734 .6 & $930 \mathrm{mp}_{\mathrm{a}} \min$ & $1080-1250 \mathrm{mp}_{\mathrm{a}} \min$ & $10 \% \mathrm{~min}$ & - \\
\hline
\end{tabular}

The experiments were conducted on Friction welding machine and the joints formed are shown in fig.2., below. 


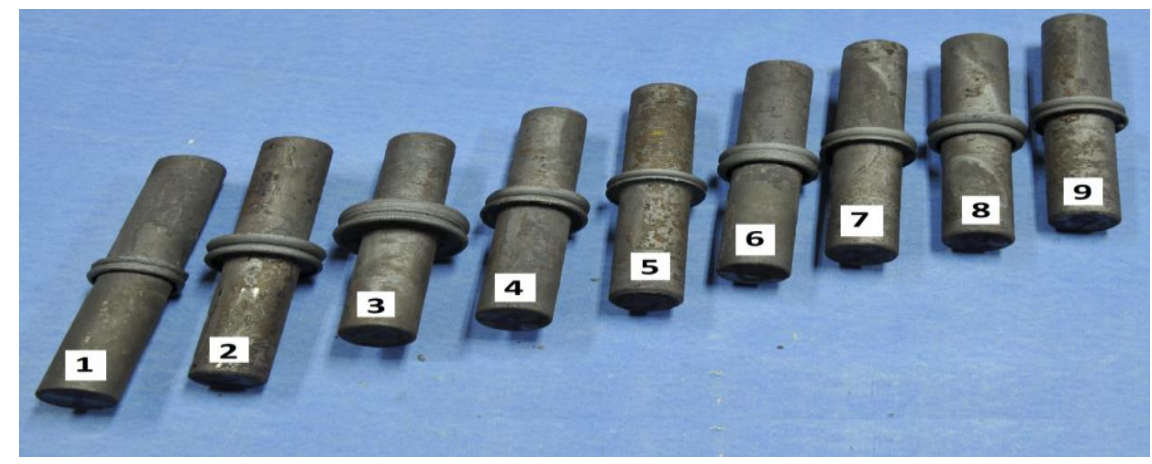

Fig.2. 15CDV6 Alloy Steel Welded Joints

In friction welding, generally surface preparation is not considered as a major requirement as surface irregularities are removed by scoring action and the debris get removed in flash. However Yilbas [6] and Hasui and Matsui [7] showed the surface preparation can significantly affect the joint strength. In this work, the contact surfaces of the round rods were machined before welding to produce smooth as well as oxide-free surfaces this also ensures perpendicularity which is also important for achieving sound weld joints.

The process parameters mainly considered in this current work are friction force, forge force, rotational speed, and burn off length, Taguchi design of experiments is chosen to optimize the process parameters a Taguchi $\mathrm{L}_{9}$ Orthogonal array was selected for the investigation of the effects of process parameters, the parameters design of Taguchi method provides a simple, systematic and efficient methodology for process parameters optimization [11], based on preliminary welding trials, three levels were considered for each of the process parameters. Working range of each parameter was decided upon by inspecting the micro structure (cross-section of welding region) for a smooth appearance without any visible defects [13]. The details of process parameters and their levels are shown below in Table 4.

Table 4. Control Factors

\begin{tabular}{lccc}
\hline Parameters (Factors) & level 1 & level 2 & level 3 \\
\hline Friction force (kN), A & 5 & 10 & 15 \\
Forge force (kN),B & 15 & 25 & 45 \\
Rotational speed (rpm),C & 1000 & 1500 & 2000 \\
Burn off (mm), D & 2 & 4 & 6 \\
\hline
\end{tabular}

The friction welding experiments of the material 15CDV6 alloy steel of similar joints were conducted as per the table 5, taking the impact toughness of the joint as the response parameter in a randomized order using a fully automatic continuous drive friction welding machine made by ETA-Technology Bangalore at Defence Metallurgical Research Laboratory (DMRL) Hyderabad for each combination of process parameters two trial runs were made, equal length of similar round rods were employed on both rotating side (RS) and stationary side (SS) in all the cases.

After friction welding the welded joints were made as standard specimens to the specifications and then the Impact tests were performed to the prepared specimens on Charpy Impact Testing machine of capacity (450J) made by ETA Technology at DMRL Hyderabad later on those samples were prepared for micro structural examination as per standard metallographic procedures and the resulting macro and micro structures are shown in figure 5 , and figure 6. 
Table 5. S/N Ratio of Impact Toughness

\begin{tabular}{|c|c|c|c|c|c|c|c|c|c|}
\hline \multirow{2}{*}{ Exp. No } & \multicolumn{4}{|c|}{ Parameters } & \multicolumn{2}{|c|}{ Trial } & \multirow{2}{*}{ Total } & \multirow{2}{*}{ Average } & \multirow{2}{*}{$\begin{array}{c}\text { Lager-the-bette } \\
\text { S/N ratio= } \\
-10 \log _{10}\left(1 / \mathbf{y}_{\mathbf{i}}{ }^{2}\right)\end{array}$} \\
\hline & $\mathbf{A}$ & B & $\mathbf{C}$ & D & 1 & 2 & & & \\
\hline 1 & 5 & 15 & 1000 & 2 & 53 & 54 & 107 & 53.5 & 34.5670 \\
\hline 2 & 5 & 25 & 1500 & 4 & 39 & 37 & 76 & 38 & 31.5956 \\
\hline 3 & 5 & 45 & 2000 & 6 & 22 & 20 & 42 & 21 & 26.4443 \\
\hline 4 & 10 & 15 & 1500 & 6 & 35 & 37 & 72 & 36 & 31.1260 \\
\hline 5 & 10 & 25 & 2000 & 2 & 47 & 46 & 93 & 46.5 & 33.3490 \\
\hline 6 & 10 & 45 & 1000 & 4 & 27 & 28 & 55 & 27.5 & 28.7866 \\
\hline 7 & 15 & 15 & 2000 & 4 & 38 & 39 & 77 & 38.5 & 31.7092 \\
\hline 8 & 15 & 25 & 1000 & 6 & 42 & 40 & 82 & 41.5 & 32.3609 \\
\hline 9 & 15 & 45 & 1500 & 2 & 41 & 43 & 84 & 42 & 32.4649 \\
\hline
\end{tabular}

Table 6. S/N Ratio For Factors At Different Levels

\begin{tabular}{ccccc}
\hline & Factor A & Factor B & Factor C & Factor D \\
\hline Level 1 & 30.8688 & 32.4678 & 31.9048 & 33.4603 \\
Level 2 & 31.087 & 32.4351 & 31.7288 & 30.6971 \\
Level 3 & 32.1783 & 29.2318 & 30.5007 & 29.9769 \\
Error & 1.3095 & 3.236 & 1.4041 & 3.4834 \\
Rank & 4 & 2 & 3 & 1 \\
\hline
\end{tabular}

The graphs drawn for the $\mathrm{S} / \mathrm{N}$ ratio values versus the levels for the factors $\mathrm{A}, \mathrm{B}, \mathrm{C}$, and $\mathrm{D}$ and are shown in the figure 3 below.

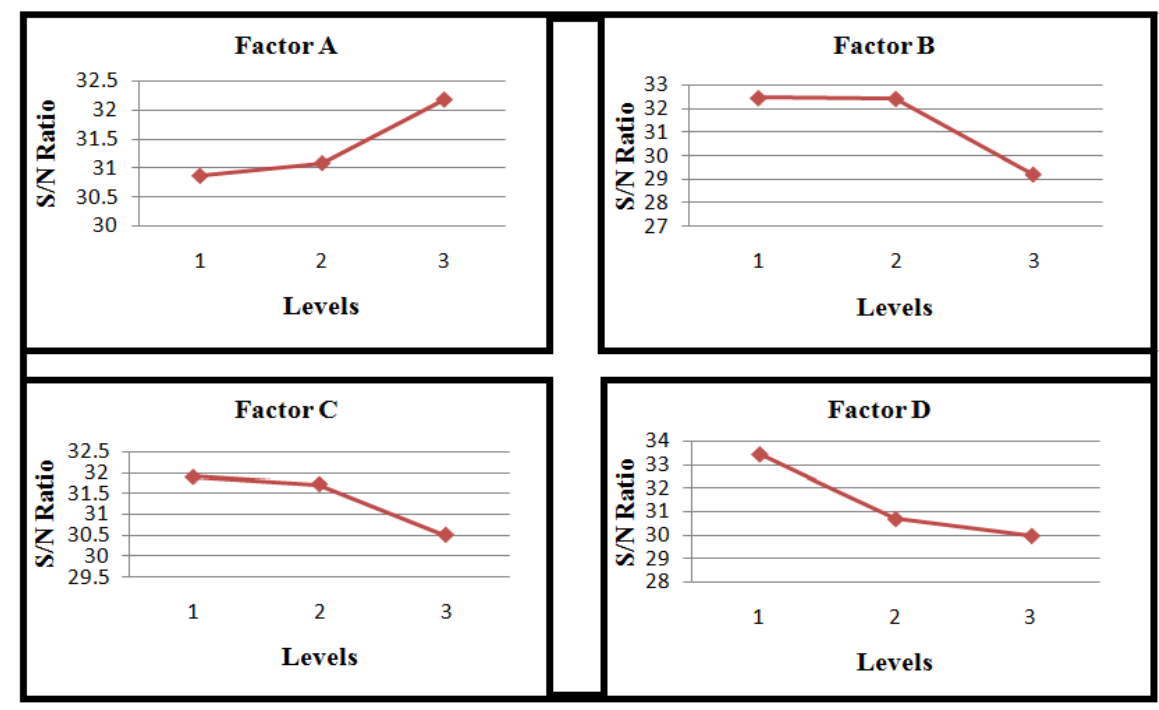

Fig.3. S/N ratio Vs Levels for Factors (A, B, C and D) 
The graphs shown in the above figure 3 , the $\mathrm{S} / \mathrm{N}$ ratio value of factor $\mathrm{A}$ is high for level 3 but according to the value of its F-ratio it is pooled because of its poor significance as shown in table 7, and as the factor B has low significance where as the $\mathrm{S} / \mathrm{N}$ ratio values of factors $\mathrm{C}$ and $\mathrm{D}$ are high at level 1 . The higher the value of $\mathrm{S} / \mathrm{N}$ ratio indicates the high impact toughness.

Table.7. ANOVA Analysis

\begin{tabular}{cccccc}
\hline $\begin{array}{c}\text { Process } \\
\text { parameter }\end{array}$ & DOF & Sum of squares(SS) & $\begin{array}{c}\text { Mean sum of } \\
\text { square(MSS) }\end{array}$ & F-ratio & $\begin{array}{c}\text { Percentage } \\
\text { contribution }\end{array}$ \\
\hline A & $(2)$ & $(48.78)$ & -- & Pooled & 00.00 \\
B & 2 & 586.11 & 293.055 & 46.29 & 39.25 \\
C & 2 & 86.444 & 43.222 & 6.82 & 5.78 \\
D & 2 & 759.110 & 379.555 & 59.96 & 50.84 \\
Error & 2 & 12.67 & 6.335 & & 4.13 \\
\hline Total & 8 & 1493.11 & & & 100.00 \\
\hline
\end{tabular}

\section{Results And Discussion}

\subsection{Process Parameter Optimization}

The Impact test results on the welds made using various process parameters combinations are listed in Table 5. For a given process parameter combinations significant differences ranging from $21 \mathrm{~J}$ (Joules) to $53.5 \mathrm{~J}$ were observed in impact toughness among the various welds, indicating that the process parameters influence the quality of the welded joints. Among the 9 welded samples $S_{1}$ and $S_{3}$ showed the highest $(53.5 \mathrm{~J})$ and lowest (21 J) impact toughness values respectively. Three base materials impact toughness is evaluated and taken the average value the impact toughness of the welds in all the cases were found to be more than the average value of the impact toughness of the base material $(18.33 \mathrm{~J})$.

The aim of this study is to evaluate the effects of the process parameters on impact toughness of the joint. Towards this study, Analysis of variance (ANOVA) was performed using the impact toughness as the response parameter (bigger-the-better), following standard ANOVA procedure. Table 7, summarizes the ANOVA results, from these results as can be seen, forge force and burn off length have the statistically significant influence on impact toughness of the joint. Among these four, forge force and burn off length have the strongest effect on joint strength with 95\% confidence level. On the other hand, the effect of rotational speed, within the parameter range selected in this study was found to be insignificant and the parameter friction force is pooled as its f-ration is not falling in the considerable value.

The result shows that a combination of low level of forge force and also low level of burn off length [10] ensures at the weld interface helps in achieving the minimum plastic deformation required as explained in stage III. Based on the result obtained in this work a strong joint with high impact toughness can be achieved at the low levels of both the parameters, forge force and burn off length. It should be noted that the optimum parameters reported here are specific to the material and its diameter used in the present work. Further the results were also dependent on the machine-specific as certain variables like brake timing, upsetting speed which can be of considerable influence on the outcome of the process.

\subsection{Macro Structures}

The welded joints were made as standard specimens to the specifications and then the Impact tests were performed to the prepared specimens on Charpy Impact testing machine of Zwick Roell company of 450J capacity at Defence Metallurgical Research Laboratory (DMRL) Hyderabad, later on those samples were prepared for micro structural examination as per standard metallographic procedures and the resulting macro 
and micro structures are shown in fig.4., and fig.5.,

The macro structures of nine different friction welded samples are shown in Figure 4, and with a magnification of 6X, the joints of the welds are all defect free and the samples S3, S6 and S8 exhibited the lower impact toughness. The S3 can be related to the high flash and the sample S6 also of little high flash which is an indication of more plastic deformation due to more heat generation, on the other hand S1 showed less amount of flash due to less plastic deformation and gaining the fine grain structure, of all the nine (9) samples $\mathrm{S}_{3}$ sample has more flash and more plastic deformation gaining coarse grain structure.
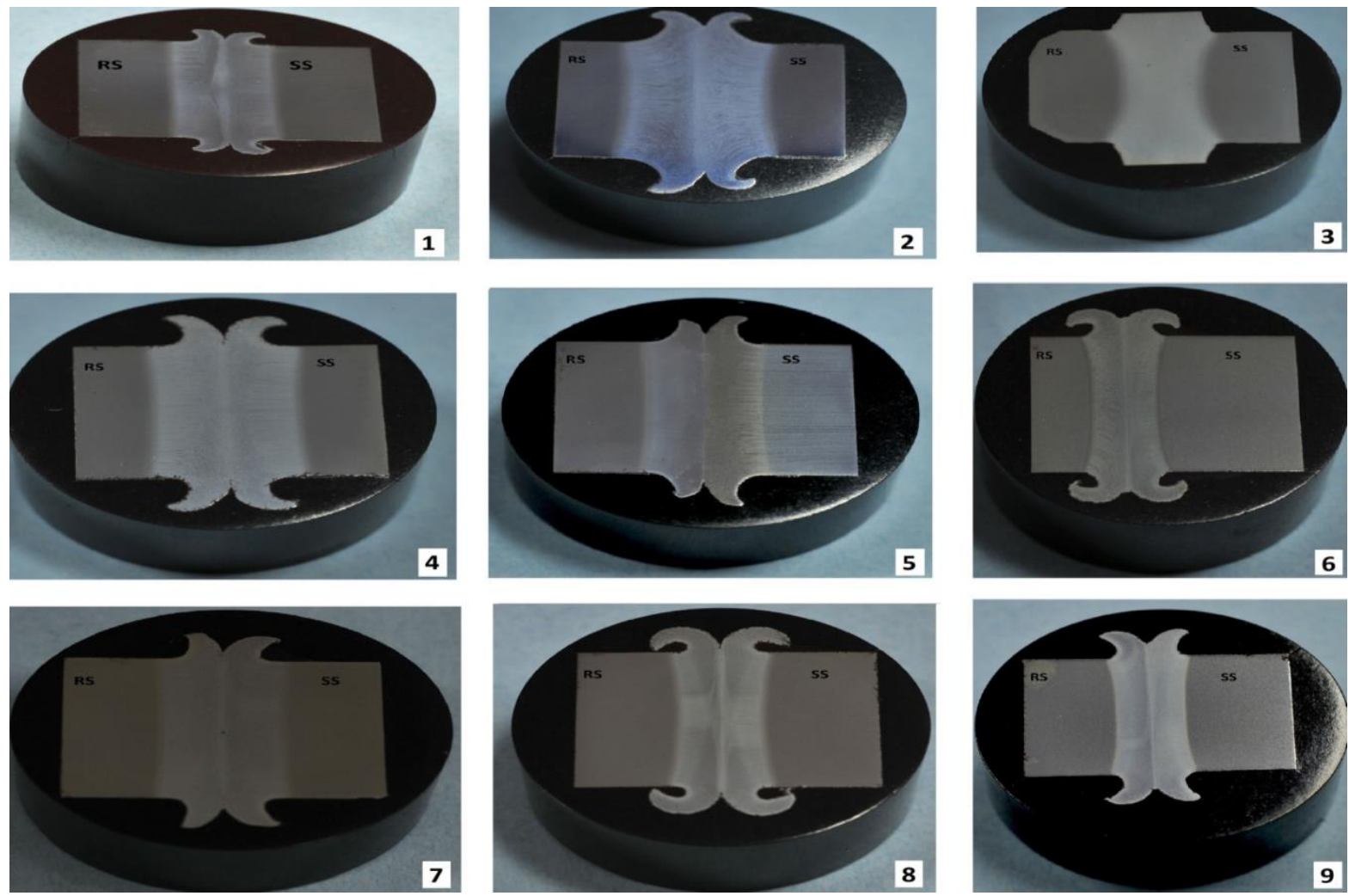

Fig.4. Macro Structures of Samples 1 to 9.

\subsection{Micro Structures}

The micro structures of sample S1 having the high impact toughness and the sample 3 has low impact toughness among all the nine samples, by observing the microstructure of sample 1 it is of fine grain structure and is due to low friction force and less rotational speed causing little flash with less plastic deformation its cooling takes place rapidly giving fine grain structure with more impact toughness whereas the sample 3 welded with high parameter levels of friction force and high rotational speed which results more plastic deformation with high flash which cools slowly resulting coarse grain structure giving low impact toughness [9] the micro structures of sample 1 and sample 3 at regions corresponding to Centre and Mid-Centre are shown in fig.6. 

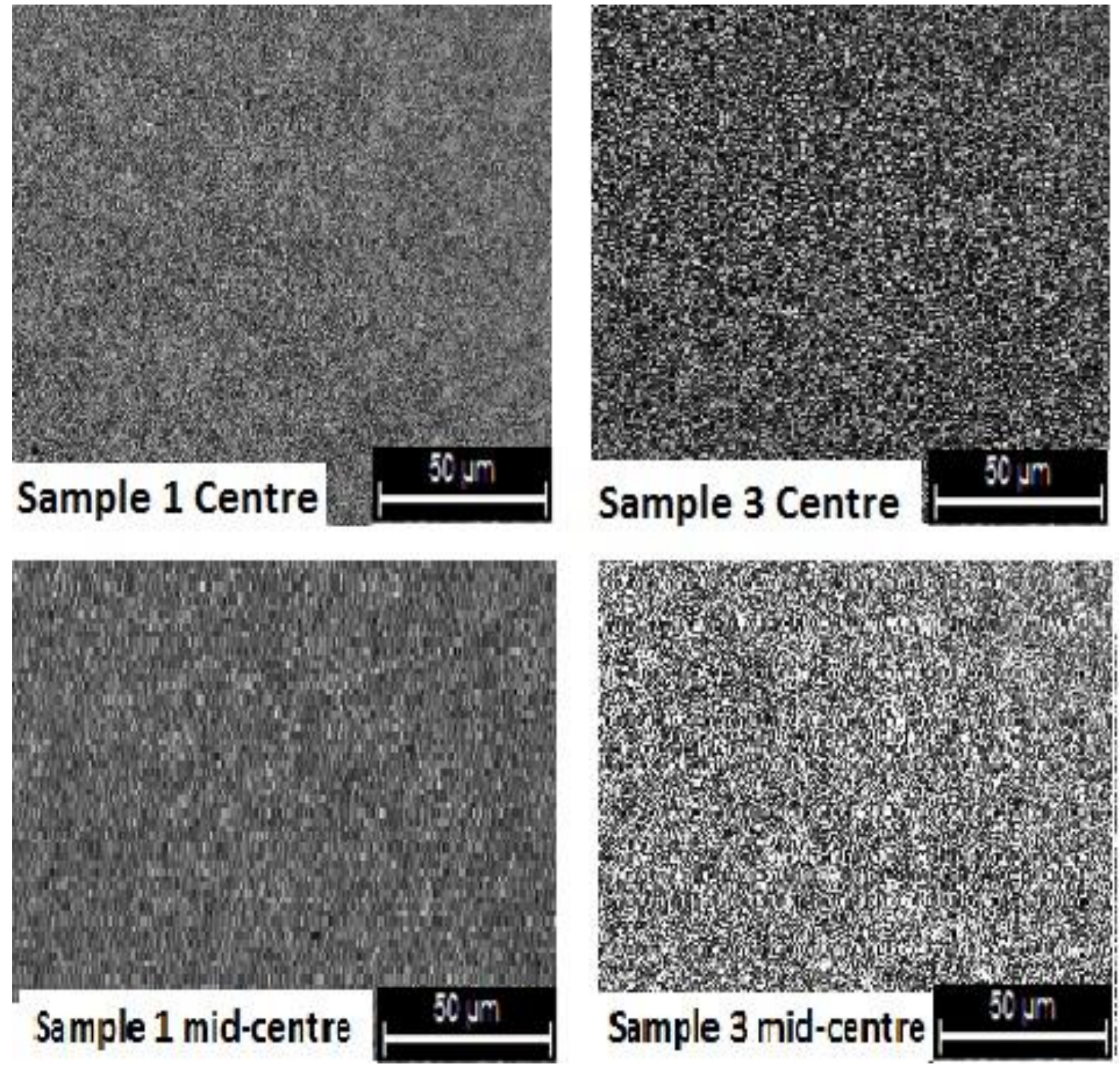

Fig.5. Micro Structures of 15CDV6 Alloy Steel Specimens 1 and 3 from Centre and Mid-Centre

\section{Conclusions}

The graphs obtained in this study explains the variation of various process parameters, Friction Force (A), Forge Force (B), Rotational speed (C) and burn-off (D) with signal to noise (S/N) ratio and also based on the results obtained it is concluded that the experimental investigations on the process parameters of $15 \mathrm{CDV} 6$ alloy steel reveals that the sound joints of 15CDV6 alloy steel with the maximum Impact toughness are achieved with a joint efficiency of $95 \%$ in pre-heat treated condition with careful selection of process parameters. Forge force $(15 \mathrm{KN})$ and Burn off length $(2 \mathrm{~mm})$ are the two most significant parameters are recommended to weld 15CDV6 alloy steel of $17 \mathrm{~mm}$ diameter round rods. In all the cases, the welds showed considerable differences in the amounts of flash and burn off with micro-structural differences from the interface to both RS and SS. 


\section{Acknowledgements}

The authors acknowledge and profoundly thank the authorities of DMRL Hyderabad for experimentation and testing and the Technical staff for their cooperation in carrying out this work.

\section{References}

[1] Hakan Aydin 1, Ali Bayram2, Ugur Esme 3, Yigit Kazancoglu 4, Onur Guven5 “Application of gray relation analysis and Taguchi method for parametric optimization of friction stir welding.

[2] M. N. Ahmad Fauzi*, M. B. Uday, H. Zuhailawati, A. B. Ismail, Microstrcuture and Mechanical properties of alumina-6061 aluminum alloy joined by friction welding "Materials and Design".

[3] Shubhavardhan RN 1, Surendran 2, "Friction welding to join dissimilar metals" The International journal of Advanced Manufacturing engineering.

[4] Mumin SAHIN "Friction welding of different Materials" INTERNATIONAL SCIENTIFIC CONFERENCE.

[5] Midling OT, Grong O.A. process model for friction welding of Al-Mg-Si alloys and Al-Sic metal matrix composites-1.HAZ temperature and strain rate distribution. Acta Metal Mater 1994; 42(4):1595-609.

[6] Bekir S Yilbas, Ahmet Z sahin, Ali coban, Abdul Aleem BJ, Investigation into the properties of friction welded aluminium bars. J mater Process Technology.

[7] Atsushi Hasui, Takashi Matsui. On the effect of faying face condition on weldability in friction welding Trans Jpn Weld soc 1987.87. Ross PJ. Taguchi techniques for quality engineering, New Yark.

[8] G.P. Rajamani, M.S. Shunmugam, and K.P Rap. Parameters optimization and properties of Friction welded quenched and Tempered Steel.

[9] Microstructure and Tensile properties of friction welded aluminum alloy AA7075-T6. H.Khalid Rafi, G.D. Janaki Ram, G.Phani kumar, K. Prasada Rao. Materials and Design.

[10] K. Boonseng, S.Chainarong, C.Meengam. Microstructure and Mechanical Properties of Friction welding in SSM356 Aluminium Alloys. International Journal of Emerging Trends in Engineering Research.

[11] Avinash S. Pachal 1, Amol bagesar 2. Taguchi Optimization of Process Parameters in Friction welding of 6061 Aluminum Alloy and 304 Steel. International Journal of Emerging Technology and Advanced Engineering.

[12] Sandeep Kumar 1, Rajesh Kumar 2, and Yogesh Kumar Singla 2. To study the Mechanical Behaviour of friction welding of Aluminium Alloy and Mild steel. International Journal of Mechanial Engineering and Robotics Research.

[13] M.Jayaraman1, R.Sivasubramanian2, V.Balasubramanian3, and A.K.Lakshiminarayana.

\section{Authors' Profiles}

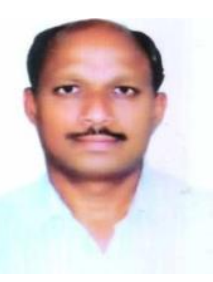

Mr. D. Raji Reddy obtained bachelor degree from Associated Member of Institute of Mechanical Engineers (AMIME) Mumbai, India, M.E., in Automation and Robotics, From Osmania University Hyderabad, and pursuing Ph.D in Mechanical Engineering Osmania University Hyderabad Telangana state, India. He has been working as Junior Lecturer in Mechanical Engineering in the Education Department Government of Telangana state, India. 


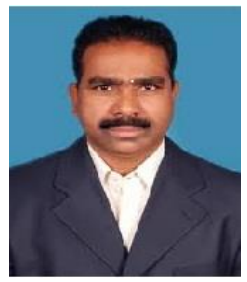

Prof. P. Laxminarayana received Bachelor of Engineering in 1989, Master of Engineering in 1995, Doctor of Philosophy degree in 2003, from the University College of Engineering, Osmania University, Hyderabad, Telangana State, India. He has published 62 papers in National and International journals and conferences. Presently he is working as a Professor in the Department of Mechanical Engineering and Dean Students Affairs, Osmania University, Hyderabad. His research area is in the field Production Engineering, Product Design and Advanced \& Micro Machining

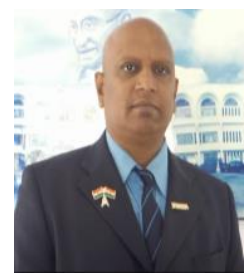

Prof. G Chandra Mohan Reddy obtained B. Tech Degree in Mechanical Engineering from Kakatiya University in 1989 and M.Tech Degree in Machine Tools from NIT Warangal in 1991 both in First Class with Distinction and Ph.D in Metal Forming from Osmania University in the year 2001. He has been presently working as Principal to the Mahatma Gandhi Institute of Technology [MGIT], Hyderabad Telangana state,India. He published 70 papers in National and International Conferences and Journals. Presented two papers at the 2nd International Conference on Advanced Tribology during 3-5 Dec'2008, organized by the National University of Singapore (NUS). He is the Chairman/ Key Note Speaker/Resource Person for many National and International Conferences, Workshops, Seminars and Short-Term Courses.

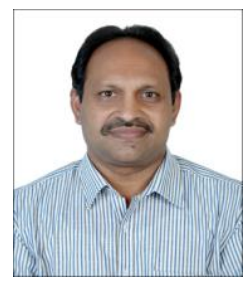

Dr. G. Madhusudhan Reddy has been working in Defence Metallurgical Research Laboratory, Hyderabad. He has made significant contributions in the area of joining of similar and dissimilar metals using fusion and solid state joining processes. He has also been instrumental in setting up of the state-of-the-art welding facilities at DMRL. He is member of the Editorial Board of Defence Technology Journal and Indian Institute of Welding Journal. He received numerous awards and among them are Best Metallurgist award from the Ministry of Steel, Government of India, DRDO Scientist of the Year Award from Ministry of defence, Government of India, Keith Hartley memorial Award of the Indian Institute of Welding, SK Mazumdar Memorial Award of the Indian Welding Society. He has more than 400 research publications. AICTE-INAE Distinguished Visiting Professor at University of Hyderabad and Andhra University. He is Fellow of the Indian National Academy of Engineering, American Society of Metals, Indian Institute of Metals, Indian Welding Society and Telangana Academy of Sciences.

How to cite this paper: D. Raji Reddy, P.Laxminarayana, G.C.M. Reddy, G.M.S.Reddy,"Process Parameters Influence on Impact Toughness and Microstructure of Pre-heat Treated Friction Welded 15CDV6 Alloy Steel", International Journal of Engineering and Manufacturing(IJEM), Vol.6, No.5, pp.38-47, 2016.DOI: 10.5815/ijem.2016.05.05 